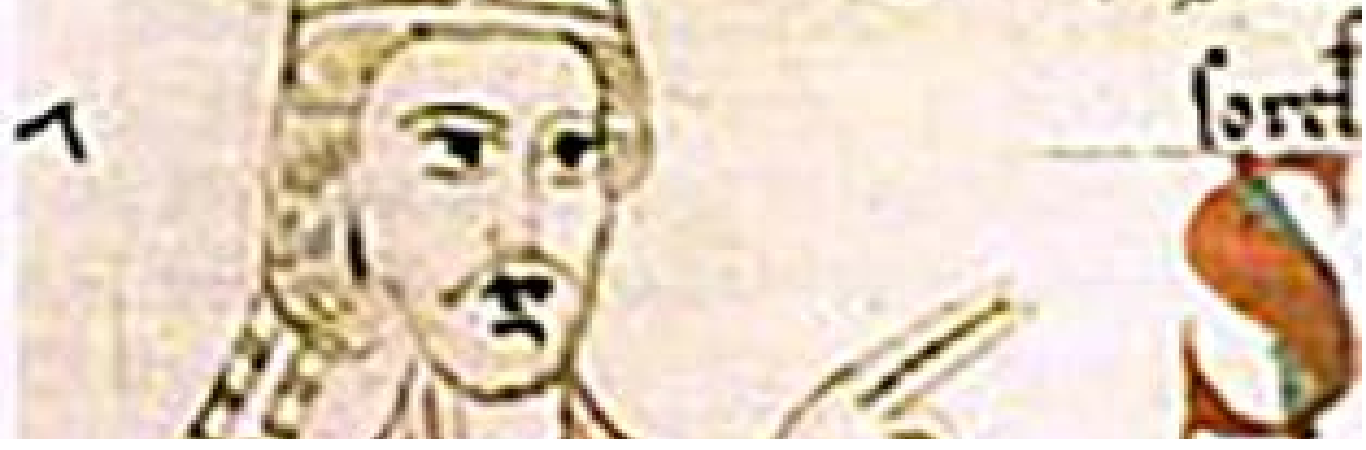

\section{"Villano malvado y cobarde": Juan Calvino, Gregorio VII y los orígenes de la corrupción pontificia}

\author{
"Evil and Coward Villain": John Calvin, Gregory VII y and the Origins of \\ Pontifical Corruption
}

\section{Resumen}

El artículo presenta un examen de las ideas planteadas en los Dictatus Papae, documento político-religioso redactado -o dictado- por Gregorio VII en la segunda mitad del siglo XI, y los confronta con las aseveraciones escritas por Juan Calvino en el cuarto libro de la Institución de la religión cristiana. Lo anterior con el fin de establecer la relación entre las afirmaciones del dictado papal y las críticas al empoderamiento del Sumo Pontífice realizadas por el teólogo francés, particularmente aquellos concernientes al pontificado de Hildebrando Aldobrandeschi

\section{Palabras clave}

Gregorio VII, Dictatus Papae, Juan Calvino, IRC, poder pontificio.

\begin{abstract}
The article presents an examination of the ideas proposed in the Dictatus Papae, political-religious document written-or dictated-by Gregory VII in the second half of the 11th century and confronts them with the assertions written by John Calvin in the fourth book of the Institutes of the Christian Religion. In order to establish the relation between the affirmations of the papal and the critics to the Supreme Pontiff's empowerment realized by the French theologian, particularly those concerning the pontificate of Hildebrando Aldobrandeschi
\end{abstract}

\section{Keywords}

Gregory VII, Dictatus Papae, John Calvin, ICR, pontifical power.

\section{DIEGO CARLO AMÉNDOLLA SPÍNOLA Universidad Nacional de México, México.}

Doctor en Historia por la UNAM. Becario Posdoctoral en el Centro de Estudios Literarios del Instituto de Investigaciones Filológicas, UNAM. Profesor del Colegio de Historia de la Facultad de Filosofía y Letras, UNAM. Autor de: "Estudiar la Edad Media desde México: Problemáticas en torno al estudio de la obra de Chrétien de Troyes desde una latitud no europea", en Armando Torres (ed.), La Edad Media desde una perspectiva Latinoamericana; «Et qui or me vaurra entendre, cuer et oreilles me doit rendre»: Espacios de lectura y público de los roman courtois de Chrétien de Troyes (ss. XII-XIII)», Cuadernos Medievales, no. 20, junio 2016.

\section{ORCID \# $\otimes$}

Recepción de artículo: 5-7-2018

Aceptación del artículo: 18-11-2018

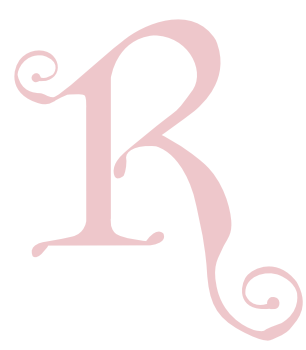




\section{Desde entonces los pontifices no cesaron jamás, ya con fraudes, ya con perfidia o por la fuerza de las armas, de adueñarse de los señores ajenos}

\author{
Jean Calvin, L'Institution de la religion chrétienne (1541)
}

\section{INTRODUCCIÓN}

Desde ya hace varios siglos, la obra escrita por Juan Calvino ha sido centro de atención y análisis de historiadores, juristas, politólogos y teólogos, entre otros. Particularmente la Institución de la religión cristiana (IRC), cuya escritura comenzó hacia 1534, es uno de los textos más copiosos del siglo XVI europeo, además de establecer, junto con otros acontecimientos, el puente entre la Edad Media y la Modernidad, como lo han señalado intelectuales como Ernst Troeltsch y Quentin Skinner, es decir, el inicio de la transformación de las estructuras Pleno y Bajo Medievales en su carácter político, religioso y social. ${ }^{1}$

Si bien en dicha obra Calvino profundizó en una amplia diversidad de temáticas por lo que un análisis minucioso de la obra presupone una investigación de mayor calado, en este artículo se ahondará en un aspecto que, si bien el autor menciona en pocas páginas, es importante para comprender, desde una perspectiva amplia, la argumentación de Calvino en torno del poder terrenal, su orden y designio divino, y, en particular, las problemáticas que encontró el jurista francés en la jerarquía eclesiástica.

En este orden de ideas, a partir del examen de las ideas planteadas en los Dictatus Papae (DP), documento político-religioso redactado -o posiblemente dictado- por Gregorio VII en la segunda mitad del siglo XI, se confrontarán con las aseveraciones escritas por Calvino en el cuarto libro de su IRC, con el fin de establecer la relación entre las afirmaciones del dictado papal y las críticas al empoderamiento papal realizadas por el teólogo francés, particularmente aquellas concernientes al pontificado de Hildebrando Aldobrandeschi.

Para lograr dicho objetivo será necesario señalar el contexto en el que el documento papal fue redactado, además de indicar los aspectos más importantes del pontificado de Gregorio VII, quien ha sido ampliamente analizado por su reforma eclesiástica. Posteriormente ubicaremos los puntos principales de los DP y los confrontaremos con lo señalado por Calvino en la IRC. Es de suma importancia señalar que, hasta donde tenemos noticiar, no existen trabajos que analicen minuciosamente la relación entre Gregorio VII, su reforma eclesiástica y la crítica que le hizo Calvino. Si bien ambas obras han sido estudiadas, los análisis se caracterizan por hacerlo de manera separada o por escudriñar de manera general la relación entre ambos documentos. No obstante, si bien es numerosa la historiografía publicada tanto por medievalistas y modernistas que ha buscado examinar tanto a los autores como a sus reformas, la presente contribución pretende trazar un puente entre ambos procesos.

\section{GREGORIO VII: INICIO Y CONCLUSIÓN DE UN LARGO PROCESO DE TRANSFORMACIÓN}

Considerado como uno de los Papas más importantes de la Plena Edad Media, Gregorio VII se caracterizó por llevar a cabo la última etapa de la reestructuración de la Iglesia plenomedieval. Dicho proceso, comenzó en el año 909 o 910 con el establecimiento de la Abadía de Cluny en cuya carta fundacional Guillermo I, conde del Mâcon y duque de Aquitania, señalaba:

Los monjes no estarán sujetos a nosotros, nuestros padres, el poder real o cualquier otra autoridad terrestre. Por Dios y ante Dios y todos los santos y el terrible día del juicio, prohíbo a cualquier príncipe secular, conde, y al propio pontífice de la sede de Roma, invadir las posesiones de los siervos de Dios, alienarlas, disminuirlas, cambiarlas, entregarlas como beneficio, o colocar algún obispo sobre ellas sin su consentimiento. Si algún hombre hace esto quede su nombre borrado del libro de la vida. ${ }^{2}$

Como es posible observar, la abadía tuvo la función de otorgar a los monjes un espacio particular para desarrollar sus actividades espirituales, donde su autoridad primara, tanto en términos territoriales como electivos, bajo la afirmación de que quien no respetase lo anterior no encontraría la Salvación. ${ }^{3}$ Asimismo, como ha señalado Dominique logna-Prat, 'Este documento no garantiza únicamente la libertad espiritual del santuario; también representa el primer reconocimiento oficial de una santidad abacial cluniacense'. ${ }^{4}$ Con ello, Cluny inauguró un largo proceso de reformación eclesiástica, cuyo fundamento se encontraba en la centralización y purificación del monacato, a partir del combate al nicolaísmo -matrimonio de los eclesiásticos ${ }^{5}$ y la simonía -compra-venta cargos eclesiásticos. Todo ello con el fin de fortalecer y robustecer las filas del poder espiritual y, en consecuencia, obtener mayor autoridad frente a las monarquías del momento. A través de la implantación de un modelo monástico basado en la Regla Benedictina, la jerarquía eclesiástica endureció sus cánones y pretendió perfeccionar la moral de los religiosos.

En este orden de ideas, como ha señalado Mayke de Jong: 'Guillermo [de Aquitania] puso a Cluny bajo protección papal, garantizando el pleno dominio de su primer abad sobre sus monjes y su propiedad, así como la libre elección de futuros abades. A partir de mediados del siglo XI, Cluny iba a jugar un papel esencial en un nuevo movimiento

1. Troeltsch 1978; Skinner 2002, Vol. IV.

2. Artola 1985, p. 88.

3. La alusión al 'Libro de la vida' refiere a aquello señalado en el versículo 3 del Apocalipsis, donde se lee: 'Recuerda, pues, cómo recibiste y escuchaste la Palabra: guárdala y haz penitencia. Si no vigilas, vendré a ti como ladrón, y no sabrás qué hora te sorprenderé. Pero tienes en Sardes algunos que han manchado sus vestidos; estos andarán conmigo con vestiduras blancas, porque son dignos. Así el vencedor será vestido con vestiduras blancas; no borraré nunca su nombre del libro de la Vida y confesaré su nombre delante de mi Padre y delante de sus ángeles'. Ap. 3:3-5. Asimismo, encontramos una referencia más en el versículo 20, donde enuncia: 'Todo el que no se halló escrito en el libro de la Vida, fue arrojado al estanque de fuego'. Ap. 20:15.

4. logna-Prat 1991, p. 241. Todas las traducciones han sido realizadas por el autor.

5. Brundage 1990, pp. 214-223. 
de reforma estrechamente asociado con el papado...'. ${ }^{6}$ Asimismo, durante los siglos posteriores, la abadía buscó obtener mayor poder a partir de una segunda etapa de Reforma, ahora con el fin de ubicarse por encima de los reyes.

La reforma cluniacense, pues, fue una respuesta los últimos años del primer milenio, cuando el papado había sido dirigido por la aristocracia. Los grupos nobles de Occidente, quienes gradualmente habían obtenido mayor poder desde la muerte de Carlomagno en 814, aunado al establecimiento de los reinos a partir de 888 como producto de la fragmentación del imperio carolingio, ${ }^{7}$ tuvieron gran injerencia en las decisiones de la Santa Sede como consecuencia del poder otorgado a los señores proveniente de la primera etapa feudal (siglos IX-X) que, si bien se caracterizaba por ser un tanto incipiente en su estructura, fue acrecentando su vigor con el paso de los años. ${ }^{8}$ En consecuencia, las familias nobiliarias lograron colocar Sumos Pontífices cuyo papel era insignificante, hasta el punto en que muchos de ellos permanecieron muy poco tiempo en el poder sin haber realizado ninguna acción a favor de la Iglesia.

Así, a partir del siglo X, la jerarquía eclesiástica promovió un proyecto de reforma extensa bajo el argumento de que lo señores feudales sometían a la sociedad, en su mayoría rural, a través de hurtos y masacres, lo cual no respetaba los cánones cristianos de época; ante sus ojos, los grupos nobles se caracterizaban por establecer un régimen tiránico y herético. En este orden de ideas, hacia el año mil los cluniacenses, de la mano de Odon I, quinto abad de Cluny (994-1048), buscaron explicar el orden creador a partir de un esquema social trifuncional, a saber: aquellos que oraban (oratores), aquellos que combatían (bellatores) y aquellos que trabajaban la tierra (laboratores), donde los primeros ocupaban el lugar más cercano a Dios, en tanto a su pureza y grandeza eclesiástica. ${ }^{9}$ Nuevamente en palabras de logna-Prat: 'Alrededor del año mil, se puede leer el breve resumen del sueño teocrático cluniacense', ${ }^{10}$ el cual se llevaría a la práctica en las décadas posteriores.

Fue en dicho contexto cuando surgió la figura de Gregorio VII. Educado en el ámbito monástico desde muy pequeño, Hildebrando Aldobrandeschi fue nombrado en 1045 secretario del papa Gregorio VI y un año más tarde ingresó al monasterio de Cluny donde las ideas reformistas de la época permearon en él. Debido a su agudeza, el monje no tardó en llamar la atención de los religiosos de alto rango. Ya en 1059, el papa Nicolás II lo nombró archidiácono y administrador efectivo de los bienes de la Iglesia, cargo desde el cual Hildebrando dio continuidad a la lucha contra la simonía y el nicolaísmo, y promovió el celibato entre los religiosos, además de fomentar la idea de que la Iglesia debía elegir a sus propios funcionarios. ${ }^{11}$ Este último punto no sólo pretendía una libertad electiva para los miembros del clero sino fortalecer la figura papal frente a lo monarcas.

Pocos años después, el 22 de abril de 1073, Hildebrando fue nombrado Papa y un par de meses después obtuvo la consagración episcopal bajo el nombre de Gregorio VII. Controversial desde el inicio de su pontificado, el nuevo heredero de Pedro se consideraba designado para ejercer las funciones de su predecesor y de la reforma misma. Como señala Thomas Bisson:

Se identificaba de forma visceral con san Pedro, de cuyo poder mediaba, - y el poder de Pedro era paternal y señorial [...] A semejanza de otros prelados cristianos, Gregorio VII había sido promovido a su egregio cargo. Se sentía como un servidor que invocaba, tanto por convicción como por fórmula, su indignidad, que realizaba protestas de humildad frente a los cargos de que actuaba movido por la ambición. ${ }^{12}$

Las palabras de Bisson son fundamentales pues, como podrá observarse más adelante, tanto la cercanía que sentía el nuevo Sumo Pontífice con Pedro así como con los papas reformadores anteriores, serían de primer orden para su proyecto político, el cual buscó enaltecer y empoderar a la institución eclesiástica, a través de una reinterpretación social, política y teológica.

\section{DICTATUS PAPAE: UNA AFRENTA AL PODER REGIO}

El proyecto reformista de Gregorio VII no tardó en materializarse en un documento oficial. En 1075, tan sólo dos años después de ser nombrado Papa, redactó los DP. Si bien dicho tipo documental, puede ser comprendido como un cuerpo doctrinal cuyo objetivo era exponer los derechos tradicionales que tenían los pontífices y, en este sentido, tenía un carácter teológico y político, el texto gregoriano se distinguió por establecer la supremacía del poder espiritual sobre el terrenal. Así, conformado por veintisiete puntos, los dictados se caracterizaron por defender el gobierno del sacerdocio en el cual el Sumo Pontífice era el soberano absoluto y único en su cargo. Esta premisa la podemos observar en varios puntos del documento, especialmente en los puntos II y VII que señalan: 'Que sólo el pontífice romano sea llamado universal'13 y 'Que le es lícito deponer emperadores' ${ }^{14}$.

En este orden de ideas, los DP pretendieron realizar una nueva sistematización de los derechos pontificales, lo cual no fue bien recibido por lo monarcas debido a que no sólo trasladaba a la figura papal a un nivel superior, sino que quitaba poder a la nobleza y la censuraba, negando a sus miembros juzgar al Papa, ${ }^{15}$ nombrar y deponer obispos. ${ }^{16}$

6. De Jong 2002, p. 172.

7. Mazel 2010, pp. 17-97

8. Bisson 2009, pp. 84-181.

9. Dicha división tripartita se encuentra en los documentos redactas por Adalberón de Laon y Gerardo de Cambrai hacia el siglo XI. Vid. Adalbero Laudensis Episcopus, Carmen Ad Robertum Francorum Regem, col. 0771-785; Gesta Pontificorum Cameracensium, col. 0021-0240B. La obra ha sido adjudicada a Gerardo de Cambrai, aunque la autoria continua siendo incierta.

10. logna-Prat 1991, pp. 251-252.

11. González 2006, pp. 188-191.

12. Bisson 2009, p. 89.

13. Gregorio VII, Dictatus Papae, II. (Citado de aquí en adelante como DP, y número del documento).

14. DP, VII.

15. $D P, X I X$.

16. $D P, I V$. 
Asimismo, el texto buscó investir al Obispo de Roma con la potestad para eximir a los súbditos de la fidelidad hacia príncipes inicuos ${ }^{17}$, lo cual trastocaba el poder feudal de los señores.

Así, a través de este documento, Gregorio VII buscó cercar el poder regio y nobiliario para establecer un pontificado universal; lo cual, se encontraba fundamentado en el punto veintitrés de los DP donde señala: 'Que el Pontífice Romano, una vez ordenado canónicamente, es santificado indudablemente por los méritos del bienaventurado Pedro, según testimonio del santo obispo Enodio de Pavía, apoyado por los muchos santos Padres según se contiene en los decretos del Beato Papa'. ${ }^{18}$ De esta manera, el papa justificaba todas sus acciones en su vicaria naturaleza, de tal suerte que no podía ser acusado de ocupar un lugar en el orden estamental que no le correspondía. ${ }^{19}$

A pesar de lo anterior, tanto el escrito papal como la Reforma Gregoriana en su conjunto no tuvieron buena recepción. Claro ejemplo de ello fue la llamada Querella de las investiduras, la cual se desató en 1076 cuando Enrique IV, emperador del Sacro Imperio Romano Germánico, no estuvo dispuesto a aceptar el menor deterioro del poder imperial y se comportó de manera indiferente ante los designios del papa. Contrario a los intereses del Sumo Pontífice, el emperador nombró titulares eclesiales en Milán, Espoleto y Fermo, además de llamar a un sínodo en Worms, en el cual se depuso al heredero de Pedro. En respuesta, Gregorio VII eximió a todos los vasallos de Enrique del juramento de fidelidad y excomulgo tanto al emperador como a todos aquellos que siguieran sus pasos. En consecuencia, el emperador buscó el perdón del papa y después de tres días le fue permitido volver a la comunidad religiosa.

Si bien como ha señalado Esther González Crespo: 'Para el papa, este episodio no fue un pulso político o jurídico, sino un cuestión espiritual y religiosa, ya que, como sacerdote, administraba la penitencia para castigar el pecado público, esperando que se produjera el arrepentimiento', ${ }^{20}$ es claro que este evento marcó una importante separación entre el Imperio y la Iglesia. Ejemplo de ello, es que en el sínodo de 1080 el emperador fue nuevamente excomulgado y depuesto debido a su carente sumisión ante la figura papal, a lo que éste respondió, apoyado por los obispos alemanes y lombardos, con la elección del antipapa Clemente III y el asedio de Roma, donde sería nuevamente coronado por el falso pontífice. Refugiado en el Castillo de Sant'Angelo, Gregorio fue rescatado por las tropas normandas y se retiró a Salerno donde habitó hasta el último de sus días.

Como hemos podido observar la figura de Gregorio VII marcó un parteaguas en la conformación política y social de la Edad Media. A partir de la escritura de dicho documento la Iglesia culminó un primer momento de reempoderamiento, el cual sentaría las bases para que durante los siguientes siglos el papado buscará consolidar el gobierno hierocrático. Si bien dicho proceso vería uno de los momentos más importantes durante el siglo XIII de la mano de Inocencio III y su autodesignación como Vicarius Christi, ${ }^{21}$ la institución papal buscaría darle continuidad durante el resto de la Plena y la Baja Edad Media, por supuesto en constante lucha con el poder regio.

Ahora bien, como hemos señalado en las primeras líneas de este artículo, nuestro interés radica en observar cómo fue leído este proceso por Juan Calvino en el siglo XVI; de tal manera que en las páginas siguientes confrontaremos el proceso reformista de Gregorio VII con lo establecido por el jurista francés en su IRC.

\section{GREGORIO VII COMO ORIGEN DE LA DECADENCIA ECLESIÁSTICA: ARGUMENTOS DE JUAN CALVINO}

Basta leer tan sólo algunas líneas escritas por Calvino para evidenciar su postura ante los últimos cuatro siglos de la Edad Media. Desde su punto de vista, aquellas centurias se caracterizaron por una decadencia eclesiástica abiertamente fraudulenta, pérfida y guiada por el uso de las armas para obtener poder sobre los señoríos ajenos. Así, en torno al origen de dicha corrupción, Calvino apuntó en el capítulo XI del libro cuarto de su IRC:

Por lo demás, si alguien quiere saber de qué fuente procede este Imperio distorsionado, cabe señalar que no han pasado quinientos años que los Pontífices estaban sujetos a los emperadores, y que no se elegía un Papa sin la autoridad del emperador.

El cambio vino en tiempos de Gregorio VII, quien, estando dispuesto a hacerlo para sí mismo, tomó la ocasión por la locura del emperador Enrique, cuarto de ese nombre. Puesto que Enrique, junto con muchas otras insolencias y actos desordenados que hizo, vendió los obispados de Alemania, o bien los distribuyó en su corte como presa. Es por eso que Hildebrando, es decir el papa Gregorio VII, quien había sido descubierto por él, tomó una cobertura honesta y favorable para vengarse. Más aún cuando parecía que tenía una buena y legitima causa de querer corregir los sacrilegios del emperador, muchos se unieron a él para ayudarlo. Por otro lado, el emperador Enrique, a causa se su mal gobierno, no era muy querido por la mayor parte de los príncipes. Al final Hildebrando mostró su maldad, ya que era un villano malvado y cobarde. Por eso, los que habían conspirado con él, lo abandonaron. Sin embargo, hizo tanto que sus sucesores no sólo pudieron liberarse del sometimiento, sino que mantuvieron a los emperadores en sus ataduras. ${ }^{22}$

Las palabras de Calvino remiten directamente en el punto IV de los DP sobre el derecho papal para nombrar y deponer obispos, y el punto XXVII en cual concede al Sumo Pontífice el poder de eximir a los súbditos de la fidelidad hacia príncipes malvados. ${ }^{23} \mathrm{Si}$ bien pareciera que estas dos anotaciones permiten trazar claramente la relación entre el documento

17. $D P, X X V I I$.

18. DP, XXIII

19. Véase $n .9$.

20. González 2006, p. 191

21. Debido a los objetivos de este artículo, no analizaremos el pontificado de Inocencio III y la consolidación de la hierocracia pontifical. Al respecto, véase Théry 2007.

22. Calvin, Institution de la religion chrétienne, IV, XI, 13. (Citado de aquí en adelante como IRC, libro, capítulo y apartado).

23. Es muy probable que Calvino conociera tanto los DP como el Registrum durante su etapa formativa en la Universidad de Orleans y de Brujas, donde se 
papal y las afirmaciones de Calvino, cabe señalar que la supremacía pontificia no fue un fenómeno plenomedieval. Como ha señalado Marta García Alonso, la idea de una hierocracia no hunde sus raíces en el siglo

XI, pues casi 600 años antes Gelasio I (492-496) y Gregorio Magno (590-604) ${ }^{24}$ habían establecido las bases del papel ministerial de los emperadores, a saber: 'el emperador tendrá como misión fundamental servir a la Iglesia y vigilar para que se mantenga la paz en ella, puesto que sólo ésta asegura la paz del Estado'25. A ello, habría que añadir la afirmación que durante la segunda mitad del siglo IV ya había realizado Ambrosio, obispo de Milán, entorno a la supremacía de la Iglesia -y por lo tanto del papado-sobre los emperadores. ${ }^{26}$ Si bien no podemos comprender las afirmaciones antes señaladas desde una perspectiva lineal y mucho menos teleológica, sino como un fenómeno que fue de amplio interés para varios eclesiásticos en diversos contextos, aún queda por dilucidar por qué señalaría Calvino la segunda mitad del siglo XI como el inicio de un pontificado execrable.

Para dar luz a esta cuestión es necesario destacar dos elementos fundamentales, a saber: las características de la superioridad papal y eclesiástica, y, por otra parte, las bases teológicas de Calvino. Sobre la primera, esta se encontraba fundamentada en el Evangelio según San Mateo, el cual dicta: 'A ti [Pedro] te daré las llaves del Reino de los cielos, y lo que ates en la tierra quedará atado en el cielo, y lo que desates en la tierra quedará desatado en el cielo'. ${ }^{27}$ En este orden de ideas, sería el Sumo Pontífice, como heredero de Pedro quien poseería el poder gubernamental. Asimismo, como ha explicado Walter Ullmann:

Esta doctrina hierocrática en virtud de ser aplicada se convirtió en la base gubernamental del papado. Lo que la doctrina pura declaró que se debía hacer, ahora se esta haciendo. La doctrina hierocrática surgió en la forma del sistema hierocrático, la esencia de la cual es la concepción de la Iglesia universal como un cuerpo corporativo y político, que comprendía a todos los cristianos. Esta es la societas christiana, para utilizar la terminología distintiva de Gregorio VII, en la que la autoridad del pontífice romano tiene dominio; en la que el mandato del papa crea efectos vinculantes. ${ }^{28}$

Sería, pues el Sumo Pontífice, en tanto heredero de la silla de Pedro, quien debía guiar y regir a la sociedad cristiana a partir de la promulgación de leyes, con el fin de conservar el orden y crear vínculos entre los miembros del cuerpo social. Por otra parte, se postulaba la necesidad de jerarquizar a la sociedad con base en sus funciones y cargos, lo cual aseguraría el orden y la paz de la comunidad. ${ }^{29}$ En consecuencia: 'dado que la fe en Cristo era el lazo que unía a toda la Iglesia; y puesto que la exposición de esta fe era tarea del clero, la misma ley, como regulador externo de la sociedad, debía basarse en esa Fe'. ${ }^{30}$ Dichas premisas apuntaban a la carente pericia de los reyes para dictar las leyes y, con ello, conservar el orden social. En cambio, serían los eclesiásticos, dirigidos por el Papa, quienes se encargarían de impartir justicia, mientras que los reyes serían los encargados de proteger al clero bajo las órdenes del heredero de Pedro.

En este orden de ideas, si bien a lo largo la Antigüedad Tardía y la Alta Edad Media las ideas de la supremacía papal ya habían impactado en Occidente, no fue hasta la llegada de Gregorio VII -y hasta Inocencio III (1198-1216)- cuando éstas comenzaron un proceso de paulatina consolidación, a partir de los postulados del papa reformista. Así, el Sumo Pontífice no sólo fue parte de una larga transformación interna y externa de la Iglesia, sino que conjuntó las ideas de un orden jerárquico encabezado por el sucesor de Pedro, quien en su figura descansaría la auroritas y la potestas y, por lo tanto, el derecho de dictar ley en beneficio de la sociedad. En síntesis como ha señalado Ullmann: 'Lo que intentó el papado fue la implementación de los principios hierocráticos, es decir, la traslación de los principios abstractos a acciones gubernamentales concretas' ${ }^{31}$

Frente a dichas ideas, Calvino fundamentó su argumentación a partir de la lectura y exégesis de la Epístola de Pablo a los romanos, la cual en su versículo 13, apunta:

Todos deben someterse a las autoridades superiores; pues no hay autoridad que no venga de Dios; y las que hay, han sido constituidas por Dios. Así que el que se opone a la autoridad, se opone al orden establecido por Dios, y los que se oponen, se hacen reos del juicio. Los magistrados, en efecto, no deben infundir temor al que obra bien, sino al que obra mal. ${ }^{32}$

Como es posible observar, para el jurista francés el lugar de los monarcas y príncipes era otorgado por Dios, de manera que estos no sólo eran necesarios para mantener el orden terrenal, sino que habían sido elegidos por Él para proteger a la sociedad. Lo anterior puede ser corroborado en su Comentario a la Epístola a los romanos, específicamente al versículo 13, cuando señala:

Él [el Apóstol Pablo] llama poderes Superiores, no a las Soberanos y a los que obtienen un imperio o dominio soberano, sino a aquellos que tienen alguna preminencia por encima de los otros. Ellos son llamados Magistrados con respecto a los demás y no a una comparación entre ellos. Me parece cierto aducir, que el Apóstol a querido con esa palabra, quitar la frívola curiosidad de los hombres, quienes están acostumbrados a preguntar frecuentemente, con qué derecho los que tienen el gobierno de los reinos y señoríos han adquirido este poder que tienen, pero debe ser suficiente que ellos presiden. Porque no han subido a este alto grado por su propia virtud, sino que han sido puestos por la mano del Señor [...] La

dedicó al estudio del Derecho.

24. Gelasio I, De libris recipiendis et non recipiendis a Gelasio papa cum episcopus anno circiter 496 habitum, 59, cc. 163A-164B; Gregorio I, Epistola I, 45, t. 1, pp. 71-72, Epistola III, 52, t. 1, pp. 208-210, Epistola XIII, 15, t. 2, p. 383.

25. García 2008, p. 82.

26. San Ambrosio de Milán, Contra Auxentius, PL, 16, pp. 1007-1018.

27. Mt. 16: 18.

28. Ullmann 1955, p. 271.

29. Véase n. 9.

30. Ullmann 1999, p. 98.

31. Ullmann 1955, p. 262.

32. Rom., 13:1-7. 
razón por cual debemos estar sujetos a los Magistrados, es porque ellos son establecidos por la ordenanza de Dios. Si le agrada al Señor gobernar el mundo de esta manera, cualquiera que menosprecia y rechaza el poder, se esfuerza por derrocar el orden de Dios, e incluso resiste a Dios. ${ }^{33}$

Dicha afirmación, también puede ser encontrada en la IRC, donde Calvino, basado en el Libro de los Proverbios, ${ }^{34}$ estableció que la autoridad de los reyes y superiores no era fruto de la 'perversidad de los hombres', en cambio ésta emanaba de la Providencia de Dios y el orden que dictaba, es decir de la manera en que 'le gusta dirigir el gobierno de los hombres'. ${ }^{35}$ En consecuencia, serían los reyes, sometidos únicamente a la autoridad de Dios, quienes desde su lugar de poder se encargarían de honrar a Cristo para que Éste estuviera presente entre los gobernados. Como señaló el reformador francés, claro ejemplo de ello se encontraba en las figuras de David e Isaías quienes habían sido servidores de la justicia divina, como podía ser constatado en el Libro de los Salmos y el Libro de Isaías. ${ }^{36}$

Al confrontar dichas afirmaciones con las ideas establecidas por la teoría hierocrática, así como por Gregorio VII en los DP, es posible establecer que a través del empoderamiento eclesiástico y sobre todo del Sumo Pontífice, las figuras regias se verían desterradas de su lugar social y por lo tanto se trastocaba el orden establecido por Dios, quien desde la perspectiva del teólogo francés era el único que tenía la potestad para establecer el orden terreno y las actividades que cada persona debía llevar a cabo. Sería, pues, tal el motivo por el que Calvino adjetivaría a Gregorio como un 'villano malvado y cobarde' que, en síntesis, intentaba corromper 'el gobierno legitimo y justo del mundo' ${ }^{37}$

Asimismo, podemos añadir el punto ocho del documento papal, que sigue: 'Qué él sólo puede llevar las insignias imperiales'38. Posiblemente, este fue uno de los elementos que llamó más la atención del reformista francés y el que ocupó para establecer a la Reforma Gregoriana como origen de los males eclesiásticos. Ante sus ojos, la centralización y universalización del poder papal había tomado tintes tiránicos, los cuales estaban claramente ejemplificados con la doble excomunión de Enrique IV durante la Querella de las Investiduras y el posterior intento de someter a otros emperadores, quienes, como lo señala el dictado de Gregorio, no podían juzgar al Papa. ${ }^{39}$ Esta última premisa también fue sentenciada por Calvino cuando señaló que: 'ellos [los eclesiásticos del papado] piensan que tanto la libertad como el honor radican en esto, que ellos están libres de la justicia común'. ${ }^{40}$

Como afirmó el teólogo protestante, la consolidación papal no tardó en proyectarse en los procesos posteriores. A partir del siglo XIII se elaboró una concepción de la Iglesia como Cuerpo de Cristo, ${ }^{41}$ en la cual al Sumo Pontífice le correspondía la cabeza, 'con lo cual surgió la idea de reivindicar el dominio sobre el mundo entero en su condición de vicario de Cristo, singularizando en el papado la plenitudo potestatis' 42 y con ello la institución eclesiástica se encontraría en uno de los momentos de mayor injerencia sobre el poder monárquico de la Edad Media; se hacía patente, pues, una Iglesia extensa, económicamente rica y un papado, al parecer, omnipotente. En consecuencia, Calvino, con base en el Libro de Daniel ${ }^{43}$ y la Epístola II a los tesalonicenses, ${ }^{44}$ acusaría en diversas ocasiones al Papa de ser el Anticristo, sentencia que extendería no sólo al Sumo Pontífice reformador sino a la institución papal en general. ${ }^{45}$

Dicho señalamiento respondía a que, desde la perspectiva del teólogo reformador, el papado encarnaba al Anticristo dado que dicha institución se caracterizaba por su tiranía. ${ }^{46}$ Esta afirmación puede ser constatada en el libro IV de la IRC, cuando Calvino señaló:

Daniel y $S$. Pablo predijeron que el Anticristo se sentaría en el templo de Dios (Dan. 9, 27; Tes. 2-4): y nosotros decimos que el Papa es el capitán de este reino maldito y execrable, por lo menos en la Iglesia occidental. Y puesto que esta dicho que la silla del Anticristo estará en el templo de Dios, se significa su reinado será tal no abolirá el nombre de Cristo ni de su Iglesia. De esto se desprende que no negamos que las iglesias sobre la que domina por su tiranía, no

33. Calvin, Commentaire, pp. 463-464.

34. Prov., 8:15-16. "Por mi reinan los reyes, -y los príncipes decretan el derecho; - por mi gobiernan las autoridades, -y los grandes juzgan la tierra".

35. IRC, IV, XX, 4

36. Sal., 2:10-12 "Y ahora, reyes, comprended, instruidos jueces de la tierra. Servid a Yavé con temor, estremeceos de temblor ante Él".; Is., 49:23 "Reyes serán tus ayos, -y princesas tus nodrizas. -Rostro en tierra se postrarán ante ti, - y lamerán el polvo de tus pies. - Y sabrás que yo soy Yavé, - que en los que en mi esperan no serán confundidos".

37. Calvin, Commentaire, p. 464.

38. DP, VIII.

39. Mínguez 2009.

40. IRC, IV, XI, 15.

41. logna-Prat 2010, pp. 57-68.

42. García 2008, p. 84

43. Dan, 9:27 "Hará una firme alianza con muchos durante una semana; y a la mitad de la semana hará cesar el sacrificio y la oblación; y en el Templo estará la abominación de la desolación. Y esto hasta que la destrucción decretada se precipite sobre el devastador".

44. 2Tes, 2:3-4. "Que nadie os engañe de cualquier forma que sea. Porque primero tiene que venir la apostasía y manifestarse el Hombre impío, el hijo de la perdición. El Adversario, el que se eleva por encima de todo lo que lleva el nombre de Dios o recibe culto, hasta llegar a sentase en el santuario de Dios, haciéndose pasar por el mismo Dios".

45. Esta cuestión encuentra sus prolegómenos en los valdenses, John Wycliffe, Jan Hus y Martín Lutero, entre otros. Al respecto, véase Cortés 2006, pp. 17-186.

46. Cabe destacar que este concepto no era novedoso para el siglo XVI; ya en tiempos del papa Gregorio y durante las décadas subsecuentes, la noción de tiranía y su relación con los dirigentes había sido puntualmente explicada. Posiblemente una de las obras más importantes sobre el tema sea el Policraticus de Jean de Salisbury. Publicado hacía 1159, en el libro IV el obispo de Chartres desarrolló las diferencias entre el tirano y el príncipe, además de las actitudes que debían caracterizar a este último -obediencia a la ley, castidad, humildad y temor a Dios, etc.- para no caer en actos tiránicos. Juan de Salisbury, IV, pp. 305-344. 
sigan siendo iglesias, pero decimos que las han profanado por su impiedad, que las ha afligido por su dominación humana, que las ha envenenado con doctrinas falsas y maliciosas, y casi condenado a muerte, hasta el punto que Jesucristo está medio enterrado allí, el Evangelio está ahogado, la cristiandad es exterminada, el servicio a Dios está casi abolido. ${ }^{47}$

En este orden de ideas, cabe destacar que para Calvino la tiranía del papado no sólo se ejercía en términos materiales, sino espirituales. Lo anterior fue redactado en el mismo IV libro de la IRC, donde a partir de la exegesis del Libro del Apocalipsis, el teólogo reformador, apuntó: 'De aquí infiero que es más bien una tiranía sobre las almas que sobre los cuerpos, que se suscitará contra el reino espiritual de Cristo. En segundo lugar, que esta tiranía es tal, que no abolirá el nombre de Cristo de su Iglesia, sino que esta escondido bajo la sombra de Jesucristo, y bajo el triunfo de su Iglesia, como una máscara' ${ }^{48}$

Finalmente, es necesario profundizar en los elementos que llevaron a Calvino a afirmar que la Iglesia estaba guiada por el uso de las armas. A pesar de que esta aseveración no tiene que ver directamente con los DP, sí es parte del proceso reformista iniciado en la segunda mitad del siglo XI. En este sentido destaca el llamamiento que el mismo Gregorio VII hizo a príncipes y caballeros, para actuar en contra de los clérigos simoniacos y nicolaítas, si fuese necesario, con el uso de la fuerza. ${ }^{49}$ Lo anterior puede ser corroborado en la epístola del 13 de enero de 1075, donde el Sumo Pontífice señaló al duque Rodolfo de Suabia y a Bertoldo I, duque de Carintia, la necesidad de combatir a los clérigos 'Simoniacos y fornicarios'. ${ }^{50}$

Si observamos el proyecto de consolidación eclesiástico, es evidente que un aspecto fundamental fue la sacralización de la violencia. ${ }^{51}$ Ya desde finales del siglo XI el mismo Gregorio VII había especificado la necesidad de unificar a los países cristianos en contra del islam, lo cual fue retomado por el papa siguiente, Urbano II, cuando el 27 de noviembre de 1095 en el concilio de Clermont llamó a la primera cruzada. ${ }^{52}$ No obstante la cruzada tenía el fin de recuperar Jerusalén, ésta también fue un motivo para que la Iglesia pudiera administrar el uso de la violencia a través instituciones como la Guerra Santa y la Guerra Justa, ${ }^{53}$ las cuales, si bien ya habían sido creadas con anterioridad, encontraron su materialización en el proceso de las cruzadas que se llevaron a cabo durante casi setenta años. ${ }^{54}$ Ambas categorías postulaban que el uso de la violencia era legítimo en tanto que fuese usada cuando se atacaba a la Iglesia -Guerra Justa- o a la religión -Guerra Santa. Así, los caballeros se dirigirían a recuperar Tierra Santa y a cambio recibían indulgencias.

Como es de suponerse, con base en estas ideas no sólo fueron atacadas las comunidades de musulmanes y judíos, sino todo aquel que la Iglesia concibiera como un enemigo del cristianismo; entre ellos podían estar príncipes, reyes y señores feudales. En consecuencia, mediante el uso de las armas la Iglesia se hizo de grandes señoríos, sacralizó la violencia e hizo de la caballería un medio para obtener beneficios materiales y espirituales, aspecto que fue analizado siglos después por Calvino en la IRC.

Desde la perspectiva el reformista francés, el uso de la violencia debía ser observado desde un elemento anterior, a saber: la legitimidad de la pena de muerte. De esta manera, en el capítulo IV del libro XX, se cuestionó cómo era posible que los gobernantes fuesen justos y derramaran sangre, si la ley divina prohibía matar. Las interpretaciones entre el reformador francés y papado plenomedieval no son muy diferentes, pues para el primero, el castigo ejercido por el monarca debía comprenderse como un juicio que emanaba de Dios, es decir que el gobernante no hacía nada por sí mismo sino que sólo era un ejecutor de la voluntad divina. En consecuencia, la violencia ejercida por lo reyes no iba en contra del sexto mandamiento, pues 'si los príncipes y los demás superiores comprendiesen que no hay nada más agradable a Dios que su obediencia, si quieren agradar a Dios en piedad, justicia e integridad, empléense en la corrección y castigo de los perversos'..$^{55}$ Eran los superiores, pues, quienes debían encargarse de llevar la espada y castigar a los impíos, de lo contrario serían culpables de una grave injusticia.

Empero, los reyes y príncipes no debían ser excesivamente crueles ni severos, además de no caer presos de la ira o el odio, puesto que esto podría llevar a daños mayores. En síntesis, al ser los elegidos por Dios para cuidar el orden y la justicia -ambas emanadas de Él-, lo Magistrados debían tomar las decisiones con mesura, guiados por el deseo del bien de la nación, de lo contario estarían abusando de su autoridad, pues 'mala cosa es vivir bajo un príncipe con quien nada es permitido, pero es peor vivir bajo aquel que deja todas las cosas en abandono'. ${ }^{56}$

Estas afirmaciones, explican por qué Calvino se encontraba a favor de la Guerra Justa, ya que como él mismo lo señala, esta tenía la función de conservar la paz y la calma mediante la represión de los sediciosos

47. IRC, IV, II, 12

48. IRC, IV, VII, 25.

49. Como ha señalado André Vauchez, dicha petición no fue bien recibida por el clero, el cual "estaba indignado con estas acciones inauditas y que reprochaba al Pontífice el introducir la subversión en la Iglesia". Vauchez 1985, p. 89.

50. Gregorio VII, Epistola XLV. Ad Rodulphum Sueviae, et Bertulphum Carentanum, duces, p. 396.

51. Améndolla 2013, pp. 77-92.

52. El llamado de Urbano II fue descrito por el cronista cruzado Fulcher de Chartres, quien apunto que durante el Concilio el Sumo Pontífice declaró: "Por esta razón, no yo, sino el Señor, los exhorta con ruego suplicante a que ustedes, pregoneros de Cristo, persuadan con un gran edicto a cuantos puedan de cualquier orden, tanto caballería como de a pie, tanto ricos como pobres, para que se preocupen por ayudar oportunamente a los cristianos y expulsen de nuestras regiones a esa raza perversa". Fulcher de Chartres, Historia Hirosolimitana, p. 37.

53. Flori 2003, p. 402.

54. Desde inicios del siglo XI la Iglesia llamó a la Paz de Dios y a la Tregua de Dios. Ambos procesos intentaron limitar y administrar el uso de las armas entre los caballeros con el fin de frenar las guerras privadas entre señores. Flori, 59-98. Cabe destacar que ambas instituciones encuentran su origen en el siglo $\mathrm{X}$, cuando fueron celebradas asambleas de paz por iniciativa de clérigos y principes, además de la presión monacal. Si bien las primeras asambleas se desarrollaron en la región de Aquitania, paulatinamente se fueron extendiendo por todo Occidente. Ruiz-Domènec 2004.

55. IRC, IV, XX, 10.

56. IRC, IV, $X X, 10$. 
y enemigos de la paz y, en consecuencia, ayudar a aquellos que eran victimas de la violencia. En sus palabras: 'La misma naturaleza nos enseña que el deber de los príncipes es hacer uso de la espada, no solamente para corregir las faltas de las personas privadas, sino también para defender los países a ellos confiados, si es que hay alguna agresión. Paralelamente el Espíritu Santo nos declara en la Escritura que tales guerras son legítimas'. ${ }^{57}$

Lo anterior merece ser analizado con detenimiento, pues, como puede observarse, el reformador francés no estableció una diferencia entre Guerra Santa y Guerra Justa, ya que, para él, la segunda contemplaba tanto el daño a la ecclesia como la religión. Asimismo, destaca el hecho que de que aprobara el uso de la violencia en manos de los reyes pero no por orden del papado, lo cual puede responder a que Calvino lo observaba como una institución corrupta que hacía uso de los laicos para sus propios beneficios. En este sentido, el llamado a los bellatores tanto de Gregorio VII como de los pontífices posteriores, sería interpretado de dos formas principales: primero, como un acto que beneficiaría únicamente al Papa y al crecimiento de su poder, como fue el caso de la Querellas de las Investiduras; y, en segunda instancia, como la ruptura del orden divino, pues, como se señaló líneas más arriba, serían los monarcas lo que protegerían a la religión y a su pueblo por orden directa de Dios, con el fin de preservar la paz y la justicia terrenal. Al respecto, vale la pena retomar las palabras de Christopher Tyerman, quien ha señalado que:

Gregorio VII desarrolló significativamente la teoría y práctica de la guerra santa y los santos guerreros. Aunque no era muy dado a citar literalmente a Agustín de Hipona, su leal cómplice, el obispo Anselmo Il de Lucca, en su Collectio canonum (i.e. colección de Derecho canónico) de c. 1083, reunió las teorías agustinianas sobre la guerra justa en un solo lugar, inteligible y coherente por primera vez, si bien su circulación fue limitada. Gregorio, una de cuyas citas preferida de la Escrituras era '¡Maldito es aquel quien retrae la espada de la sangre!' (Jeremías, 48:10), prefería un enfoque moral más que legal. Identificó dos formas de ocupación para los portadores de armas: una secular, egoísta y pecaminosa; la otra penitencial, justificada por derechos legítimos, lealtad hacia un señor, protección de los vulnerables o la defensa de la iglesia. ${ }^{58}$

La enunciación de Tyerman es de primer orden en tanto que destaca la importancia de Gregorio frente a la Guerra Santa y, en consecuencia, con la idea de un papado que se hacía de los milites, al parecer, con el único objetivo de recuperar el Tierra Santa. No obstante, como el mismo autor lo señala, es necesario tomar en cuenta otro aspecto, pues la antes señalada Querella de las Investiduras no sólo evidenció el poder del papado sino su carencia de legiones, así como la necesidad de protectores laicos que garantizaran su independencia y plenitud. ${ }^{59}$ Sería en este sentido, como apuntamos anteriormente, que el Sumo Pontífice caería en aquello señalado por Calvino, es decir, una institución que hacia uso de la violencia para su propio beneficio.

\section{CONCLUSIÓN}

A lo largo de las páginas anteriores, hemos podido observar que si bien la reforma eclesiástica comenzó hacia el año 910 con la fundación de la abadía de Cluny, no fue hasta la llegada de Gregorio VII que está buscó extenderse a las afueras de el cuerpo eclesiástico. Así, Hildebrando Aldobrandeschi, de formación cluniasense, se encargo de llevar a cabo la segunda etapa de la reforma cuyo fin, entre otros, fue establecer el poder papal sobre los monarcas y emperadores, es decir, comenzar el proceso para implementar las bases de un gobierno hierocrático que encontraría su momento de mayor madurez durante el siglo XIII. Dicha cuestión sería establecida en los DP y profundamente criticada por Calvino casí 500 años después, en la IRC.

Como se ha señalado, si bien ambos autores y su producción textual han sido ampliamente analizados por la historiografía, en este artículo se han analizado las razones teológicas y políticas por la que el Calvino señaló el papado de Gregorio VII como el origen de los males eclesiasticos. Así, es posible apuntar que para el reformador francés fue durante el papado de Hildebrando cuando dicha institución intentó corromper el orden divino y buscar beneficios propios por encima de los de la población. Con base en la exegesis de la Epistola de Pablo a los Romanos y el Libro de los Provervios, entre otros textos, Calvino destacó la importancia de los emperadores y príncipes como protectores de la religión, la Iglesia y la feligracia. Todo ello, frente a la teoría hierocratica fundamentada en Evangelio según San Mateo. En este sentido, si bien no existen profundas diferencias entre la sociedad tripartita medieval y las ideas de Calvino, fue el lugar que se había otorgado el Sumo Pontífice aquello que provocó las constantes críticas del reformador francés.

Asimismo, Calvino criticó el uso de las armas por parte del Sumo Pontífice, -específicamente a partir del papado de Gregorio VII-quien, como se ha hecho patente, buscó usar a la caballería para obtener mayor poder frente a los dirigentes laicos. Instituciones como la Guerra Justa y la Guerra Santa, así como el posterior llamado a la recuperar Tierra Santa por parte de Urbano II, serían ante los ojos de Calvino una nueva afrenta al orden divino, lo que haría del Papa el Anticristo.

En síntesis, los dictados papales y las ideas de Calvino plasmada en la IRC, eran totalmente opuestos; bastaría una breve mención para adjetivar a Gregorio VII como un 'villano malvado y cobarde' y con ello establecer el origen de la decadencia eclesiástica.

57. IRC, IV, XX, 11.

58. Tyerman 2007, p. 47.

59. Tyerman 2007, p. 8. 
- Adalbero Laudensis Episcopus, Carmen Ad Robertum Francorum Regem, MPL, vol. 141, col. 0771-785.

- Ambrosio de Milán, Contra Auxentius, MPL, vol. 16, col. 1007-1008

- Améndolla Spínola, Diego Carlo, Creación del modelo de caballería a través de la cultura lúdica: producción, transmisión y recepción de las obras de Chrétien de Troyes, tesis de maestría en Historia, Instituto de Investigaciones Históricas-Facultad de Filosofía y Letras-UNAM, 2013.

- Bisson, Thomas, The Crisis of the Twelfth Century. Power, Lordship, and the Origins of European Government, Princeton, Princeton University Press, 2009.

- Brundage, James A., Law, Sex and Christian Society in Medieval Europe, Chicago, University of Chicago Press, 1990.

- Calvin, Jean, Commentaire de M. lean Calvin sur l'Episte aux Romains, Ginebra, lean Girard, 1550.

- Calvin, Jean, L'Institution de la Religion Chrétienne, vol. 4, Ginebra, Labor et Fides, 1958.

- Cortés Peña, Antonio Luis (coord.), Historia del cristianismo, t. III, Madrid, Trotta, 2006.

- Flori, Jean, La guerra santa. La formación de la idea de cruzada en el Occidente cristiano, Madrid, Trotta-Universidad de Granada, 2003.

- Fulcher de Chartres, Historia Hirosolimitana (1095-1127). Crónica de la peregrinación de los francos, México, Facultad de Filosofía y Letras-UNAM, 2018.

- "Fundación de Cluny (a. 910)", en Miguel Artola, Textos fundamentales para la historia, Madrid, Alianza, 1985, p. 88.

- García Alonso, Marta, La teología política de Calvino, Barcelona, Anthropos, 2008.

- Garín, Pedro María, Temas de Derecho Eclesiástico del Estado. La "Religión" en la comunidad política desde la libertad, Bilbao, Universidad de Dusto, 2000.

- Gelasio I, De libris recipiendis et non recipiendis a Gelasio papa cum episcopus anno circiter 496 habitum, MPL, 59, cc. 163A-164B.

- Gesta Pontificorum Cameracensium, MPL, vol. 149, col. 0021-0240B.

- González Crespo, Esther, “El pontificado, de la Reforma a la Plenitudo Potestatis”, en Mitre Fernández, Emilio (coord.). Historia del cristianismo, t. II "El mundo medieval", 2ª ed., Madrid, Trotta/Universidad de Granada, 2006, pp. 183-221.

- Gregorio I, Epistola I, 45, MGH, Greg.I. Pp. Regis. Epist., t. 1, pp. 71-72.

- Gregorio I, Epistola III, 52, MGH, Greg.I. Pp. Regis. Epist., t. 1, pp. 208-210

- Gregorio I, Epistola XIII, 15, MGH, Greg.I. Pp. Regis. Epist., t. 2, p. 383.

- Gregorio VII, “Dictatus Papae”, en Miguel Artola, Textos fundamentales para la historia, Madrid, Alianza, 1978, pp. 95-96.

- Gregorio VII, Epistola XLV. Ad Rodulphum Sueviae, et Bertulphum Carentanum, duces, MPL, t. I, pp. 396b-398b.

- logna-Prat, Dominique, "Hagiographie, théologie et théocratie dans le Cluny de l'an mil”, en Les fonctions des saints dans le monde occidental (Ille-XIIle siècle), Actes du colloque de Rome (27-29 octobre 1988), Roma, École Française de Rome, 1991.

- logna-Prat, Dominique, Iglesia y sociedad en la Edad Media, México, Instituto de Investigaciones Históricas-UNAM, 2009.

- logna-Prat, Dominique, La Maison Dieu. Une histoire monumentale de l'Église au Moyen Âge (v. 800-v. 1200), París, Éditions du Seuil, 2006.

- Jong, Mayke de, "La religión", en Rosamond McKitterick (ed.), La Alta Edad Media. Europa 400-1000, Barcelona, Crítica, 2002, pp. 141174.

- Juan de Salisbury, Policratus, Madrid, Editora Nacional, 1984. 
- La Biblia, Madrid, EDAF, 1974.

- Mazel, Florian, Féodalités 888-1180, París, Belin, 2010.

- Mínguez, José María, "Alfonso VI/Gregorio VII. Soberanía imperial frente a soberanía papal", Argutorio: revista de la Asociación Cultural "Monte Irago", año 13, no. 23, 2009, pp. 30-33.

- Skinner, Quentin, Visions of Politics, vol. II "Renaissance Virtues", Cambridge, Cambridge University Press, 2002.

- Théry, Julien, "Le gouvernement romain de la Chrétienté autour de 1206: Innocent III et les débuts de la théocratie pontificale", Mémoire dominicaine, no. 21, 2007, pp. 33-37.

- Tyerman, Christopher, God's War: A New History of the Crusades, Londres, Penguin Books, 2007.

- Ullmann, Walter Historia del pensamiento político en la Edad Media, 4ª ed. Barcelona, Ariel, 1999.

- Ullmann, Walter, The Growth of Papal Government in the Middle Ages. A Study in the Ideological Relations of Clerical to Lay Power, Londres, Methuen \& Co., 1955.

- Vauchez, André, La espiritualidad del Occidente medieval (siglos VIII-XII), Madrid, Cátedra, 1985. 